\title{
Energy summation in lateral geniculate postsynaptic responses and optic tract spike responses to large light flashes
}

\author{
D. N. YOUNG, JR., C. D. HULL, and N. A. BUCHWALD \\ Departments of Anatomy and Psychiatry, Mental Retardation Research Center, NPI \\ University of California, Los Angeles, California 90024
}

\begin{abstract}
Recordings were made from the lateral geniculate nucleus and optic tract in cats. The intensity and duration of a diffuse light was varied in a manner which allowed the recording of equivalent responses to equal energy pairs of stimuli. Estimates made from these data indicated that the period of energy summation was much longer for the optic tract than for the lateral geniculate responses. The human psychophysical literature was consulted, and the lateral geniculate responses were found to parallel estimates of energy summation measured by means of a brightness matching task.
\end{abstract}

The establishment of neurophysiological correlates of perception typically requires a complex set of comparisons across species. Detailed description of the perception of various stimuli requires the precision of human psychophysical judgments, while analysis of the fine detail of the neurophysiological correlates requires the insertion of probes into brain and sense receptors of other animals. The present report describes unit responses of the optic tract and the intracellularly recorded postsynaptic potentials (PSPs) of lateral geniculate neurons of the cat evoked by large light flashes of variable intensity and duration. By utilizing the method of response equivalence, comparisons of these neural responses with human psychophysical judgments are possible. By this procedure, the neural responses to equal-energy stimulus pairs (stimuli of equal energy but different intensities and durations) can be averaged and visually examined. If they are found to be equivalent, energy summation is said to occur. The duration of the period of energy summation for each population of responses was compared with the duration of the period of energy summation estimated by two different psychophysical techniques showing different kinds of energy summation. We concluded that the brightness of matching data of Aiba and Stevens (1964) parallels the lateral geniculate responses.

This research was supported by USPHS Grants HD-05958, HD-00345, MH-07097, and HD-04612. We are grateful to Professor James P. Thomas for his help, particularly in the design and calibration of the optical apparatus. We also thank Mrs. G. Allen and Mrs. S. Leslie for histological assistance, Mr. R. Koelling for surgical assistance, and Mr. D. Weber for electronic assistance.

\section{METHODS}

\section{Surgical Preparation}

Thirty-six cats, weighing 2 to $4.5 \mathrm{~kg}$, were initially anesthetized with a short-acting barbiturate, sodium methohexitol (10 $\mathrm{mg} / \mathrm{kg}$ intravenously). The anesthetized cat was then placed in a stereotaxic frame equipped with an optical investigation unit which allowed direct exposure of the eyes to light stimuli.

After scalp incision and retraction of temporal muscles, holes were drilled in the skull for placement of electrodes in the lateral geniculate body (LG), the optic nerve, and the precruciate cortex. In most LG preparations, bipolar stimulating electrodes were placed in the optic nerve and the visual cortex. Placement of these electrodes was verified by recording light evoked potentials.

The site of entry of the lateral geniculate or optic tract pipette was prepared, as is the convention in this laboratory (e.g., Hull, Bernardi, Price, \& Buchwald, 1973). Briefly, a bone plate was removed and replaced after opening a small window and coating with silicon jelly, and lightly secured with bone wax. Following placement of the stimulating electrodes, the cisterna magna was exposed and opened. The animal was paralyzed (gallamine triethiodid $20 \mathrm{mg} / \mathrm{h}$ ), mechanically respired, and a bilateral pneumothorax performed. At this time, xylocaine jelly (Astra) was applied to all wound edges and pressure points and reapplied periodically.

\section{Light Stimulation}

The stimuli were presented in Maxwellian view. Light pulses were generated by R1131C glow modulator tubes. The current through these tubes was routinely monitored and served as a stimulus monitor. General Electric AR4 ultraviolet lamps, placed just beneath the glow modulator tubes, served as heater elements. Rise and decay times estimated for light pulses produced in this way were less than $50 \mu \mathrm{sec}$. The glow modulator tube was driven by a Grass S4 stimulator (see Young, 1973, Appendix I), which allowed variation of the duration of the light pulse. Intensity was varied by interposing appropriate Kodak gelatin neutral density filters in the light paths (Figure 1).

The light stimuli were presented to the left eye of the cats. This eye and the entire photostimulator were masked from room illumination. The pupil of this eye was dilated with homatropine hydrobromide $5 \%$, and the nictitating membrane was retracted with phenylphrine hydrochloride. The cornea was maintained in a 


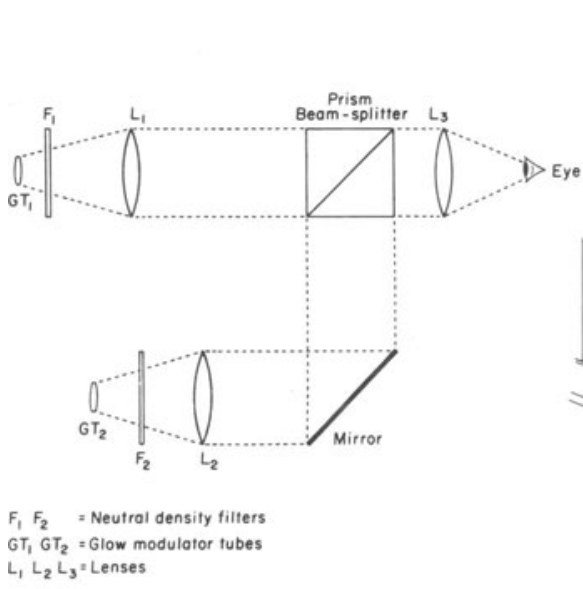

constant state by means of a nonrefracting contact lens. The right eye of the cat was protected from drying by the application of methylcellulose. During some of the early experiments, this eye was exposed to dim room illumination, but never to light from the photostimulator.

Calibration was in trolands (Td), a unit of retinal flux per unit area (Le Grand, 1968), derived from the method of Westheimer (1966). Briefly, the light was allowed to fall on a magnesium dioxide diffusion surface, and the intensity of the light reflected from this surface was measured with a Spectra Spotmeter. Noting that the image of the source was smaller than the pupil, the entire light output of the system was considered to fall onto the retina. The intensity of the light falling on the diffusing surface was measured in footlamberts, and converted to trolands according to the formulas

$$
I=\mathrm{fL} / \mathrm{D}^{2}
$$

and

$$
\mathrm{Td}=\mathrm{I} \times 10^{6} \text {, }
$$

where $I$ is in candellas, $D$ in feet from the focal point of the Maxwellian view system, and $\mathrm{fL}$ is footlamberts and TD is trolands.

The final lens of the Maxwellian view system had a focal length of $193 \mathrm{~mm}$, and a diameter of $52 \mathrm{~mm}$. The pupil was dilated to allow the entire light flash to enter. Visual angle subtended was about 15 deg.

Electrical stimulation of the optic nerve and visual cortex was used in some preparations to localize the recording site in the lateral geniculate body. Stimulating electrodes were paired insulated stainless steel wires with tips exposed about a quarter of a millimeter.

\section{Recording Procedures}

The EEG from the precruciate cortex was routinely monitored to allow an assessment of the behavioral state of the preparation. Typically, a synchronized EEG was observed. This could be desynchronized by a light pinch to the extremities or the area of the base of the tail.

Intracellular recordings were made with glass-wool-filled glass micro-pipettes (Tasaki, Tsukahara, Ito, Wayner, \& Yu, 1968) filled with $1.6 \mathrm{M}$ potassium citrate. Pipette impedences were 30 to $70 \mathrm{M}$ ㅇ. Recorded potentials were amplified by an electrometer, monitored on an oscilloscope and recorded on FM magnetic tape for later analysis.

\section{Data Processing}

Data processing was carried out in three ways: (1) Direct oscillographic tracings were made on a Varian Statos recorder. Examples of this kind of "raw" data are shown in Figure $2\left(A_{1}\right.$ and $\left.C_{1}\right)$. These traces represent individual intracellularly recorded responses of the same lateral geniculate neuron to a $25-\mathrm{msec}\left(A_{1}\right)$ and
Figure 2. Effects of light duration on lateral geniculate body "on" cell. Light intensity 100 trolands. Traces labeled $A_{1}$ and $C_{1}$ are single responses to light durations of 25 and 500 msec. respectively. Traces $A_{2}$ and $C_{2}$ immediately below the single response records are averaged frequency histograms (bin width: $20 \mathrm{msec}$ ) to the same duration stimuli. The third sets of traces $\left(A_{3}\right.$ and $\left.C_{3}\right)$ are averaged membrane responses. The vertical distance at any point between the pairs of traces represents the standard deviation. The single response was one of the 10 responses included in the averaged histograms and membrane responses. Bottom two traces are averaged histograms $\left(B_{1}\right.$ and $\left.D_{1}\right)$ and membrane responses $\left(B_{2}\right.$ and $\left.D_{2}\right)$ for stimuli of 5 and 100 msec (left and right). All recordings from the same neuron.

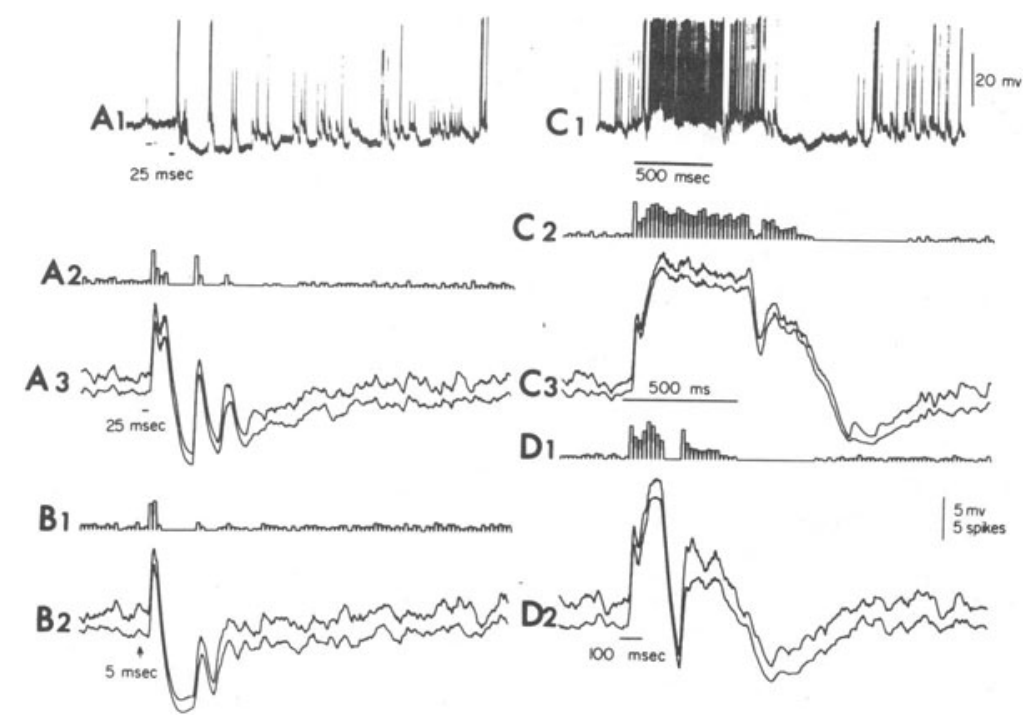




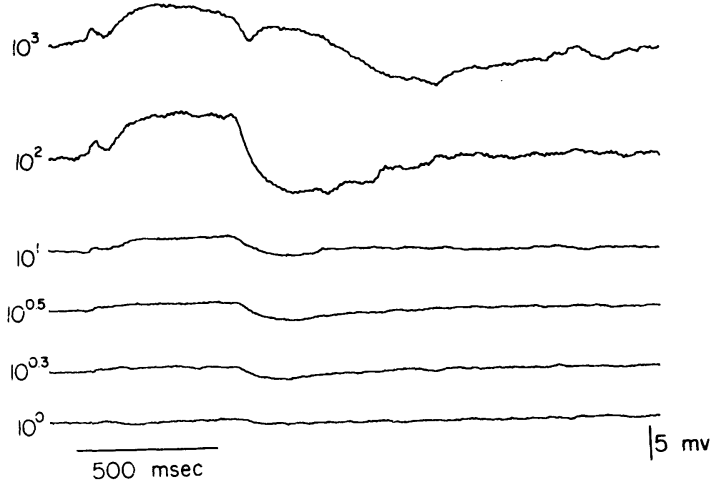

Figure 3. Effects of varying light intensity on a lateral geniculate body "on" cell. Intensities in trolands indicated at the left of each trace. Stimulus duration 500 msec indicated by solid bar. All traces are averages of $\mathbf{1 0}$ membrane responses.

500-msec $\left(C_{1}\right)$ light flash. (2) Averaged membrane responses were made with the aid of a PDP-12 digital computer. Examples of this mode of data processing are shown in Figure $2\left(\mathbf{A}_{3}, \mathbf{B}_{2}, \mathbf{C}_{3}\right.$, and $D_{2}$ ). These averages were based on responses to 10 consecutive stimuli. These traces were made by passing the data through a low-pass filter to remove the spikes. The results were then digitized (500-point total) and averaged. The vertical distances between the pairs of traces represents the standard deviation for each of the digitized 500 points. The "raw" records at the top $\left(A_{1}\right.$ and $\left.C_{1}\right)$ were one of the 10 responses averaged to obtain the middle traces below in the corresponding right and left halves of the figure. (3) Peristimulus frequency histogram. Examples of these histograms are shown in Figure $2\left(A_{2}, B_{1}, C_{2}\right.$, and $\left.D_{1}\right)$. In these cases, the spikes were counted and averaged by means of a computer program. The spike histograms were made from the same 10 responses represented by the averaged membrane responses immediately below them in Figure 2 .

\section{RESULTS}

The results are arranged to consider first the effects of the duration of the light stimulus, then the intensity of the stimulus, and last, the responses generated by pairs of stimuli of equal energy but of different intensity and duration. These topics will be considered first for intracellular responses of lateral geniculate cells, and then for responses of single optic tract fibers. The responses of "on" and "off" cells will be considered separately.

\section{Lateral Geniculate “On” Cell Responses}

Effects of increasing duration of light stimulus (intensity constant). Figure 2 shows the effect of varying the light duration on the response of a lateral geniculate "on" cell. The shortest stimulus $\left(B_{2}\right.$, $5 \mathrm{msec}$ ) evoked a response consisting of a depolarizing potential followed by a hyperpolarizing potential. As the duration of the stimulus was increased $\left(\mathbf{A}_{3}\right.$, $25 \mathrm{msec}$ ), additional potential components developed, and as the duration was increased to $100 \mathrm{msec}\left(\mathrm{D}_{2}\right)$, these components merged. A 500-msec light stimulus evoked a potential resembling the classical "on" response. The multiplicity of components seen in the cell illustrated in Figure 2 does not always occur (cf. Figưre 4, Young, 1973), although considerable response complexity is always seen.

Effects of increasing intensity of light stimulus (duration constant). Figure 3 illustrates the effect of light intensity on the averaged membrane response of a lateral geniculate body "on" cell. At the lower intensities ( $10^{\circ}$ to $\left.10^{0.5} \mathrm{Td}\right)$, a classical "on" response occurred. As the stimulus became more intense (between $10^{1}$ and $10^{2} \mathrm{Td}$ ), a complex multicomponent response was recorded. This increasing complexity with increases in stimulus intensity was typical of LGB responses.

Energy summation. Figure 4 displays averaged membrane responses from the same "on" cell illustrated in Figure 2. It provides examples of energy summation which occur with short stimulus durations. Conditions of equal intensity are in columns, of equal duration in rows. Responses are said to be equivalent where they are visually superimposable. Thus, equivalent responses which were evoked by stimuli of different intensities and durations demonstrate energy summation for the duration of the longer stimulus. For the conditions illustrated in Figure 4, one log unit of intensity has the same effect on the response as one log unit of duration (e.g., compare the top response, left column, with the bottom response, center column).

\section{Lateral Geniculate “Off”' Cell Responses}

Effects of increasing duration of light stimulus (intensity constant). Figure 5 shows a series of responses elicited by light stimuli of equal duration but varying intensities. As the stimulus duration was increased to $500 \mathrm{msec}$, the hyperpolarizing response increased in both amplitude and duration. For longer duration stimuli, its latency closely paralleled the time at which light was terminated (e.g., top two responses,

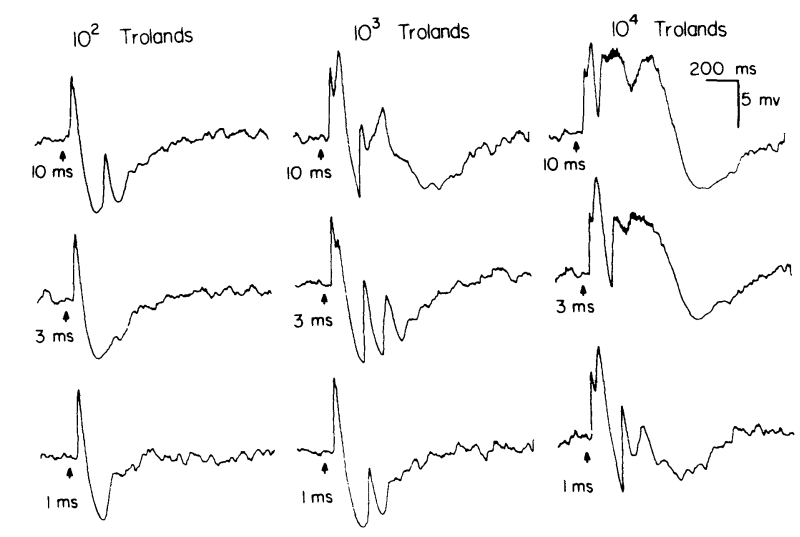

Figure 4. Demonstration of energy summation effects on lateral geniculate "on" cell. Light intensity indicated as in Figure 3. Stimulus onset and duration are indicated at the left of each trace. Note points of response equivalence to equal energy (cf. $10 \mathrm{msec}$, $10^{2}$ Td with $1 \mathrm{msec}, 10^{3} \mathrm{Td} ; 10 \mathrm{msec}, 10^{3} \mathrm{Td}$ with $1 \mathrm{msec}$, $\left.10^{4} \mathrm{Td}\right)$. Traces are averaged membrane responses. 

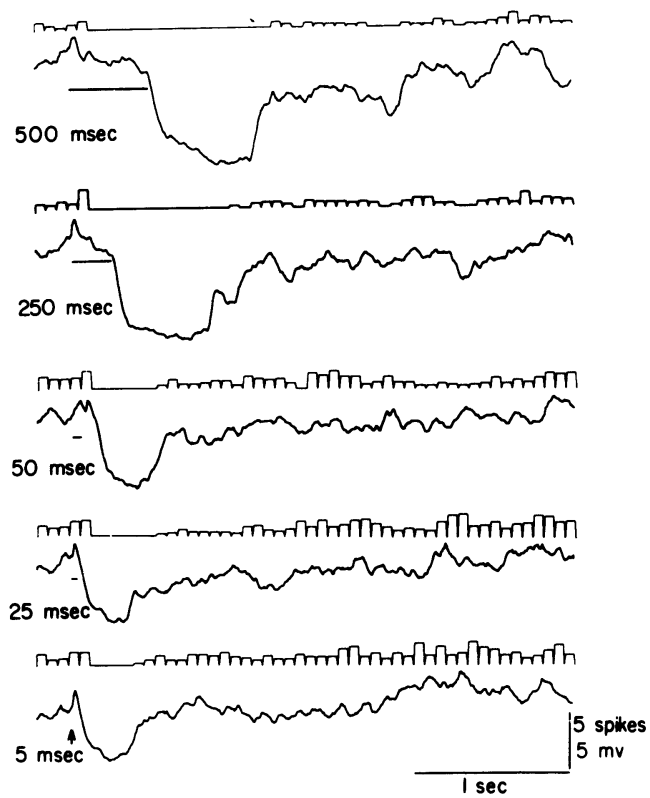

Figure 5. Effect of varying light duration on lateral geniculate body "off" cell. Light duration and stimulus onset indicated at left of each response. The top of each pair of traces is an averaged spike frequency histogram; the bottom of each pair, an averaged membrane response. Note the increase in membrane hyperpolarization, and pause in spike discharge as stimulus duration increases. Light intensity: 10 Td. Bin width: 70 msec.

Figure 5). The responses of this cell to the 500-msec stimulus illustrates disparity between the membrane potential and the spike frequency. During the light stimulus, the cell stopped firing, but the membrane did not hyperpolarize appreciably until after light offset. Additional examples of these effects may be found in Young (1973).

Effects of increasing intensity of light stimulus (duration constant). Figure 6 shows the effect of varying the intensity of a constant duration stimulus on the response of a lateral geniculate "off" cell. Averaged peristimulus spike frequency histograms have been computed which correspond in time to each averaged membrane response. (Each histogram is immediately above the corresponding membrane response.) Note that the initial response is a depolarization followed by a hyperpolarizing potential of much greater amplitude and duration. As the intensity of the stimulus was increased, both the latency and duration of the hyperpolarizing potential increased. These responses illustrate a disparity between the state of the membrane potential and the frequency of firing. For the case of the most intense stimulus, the firing rate dropped to a very low level during the course of the stimulus, but the membrane did not become clearly hyperpolarized until nearly a second after stimulus offset.

\section{Optic Tract “On” Fiber}

Figure 7 displays averaged peristimulus frequency histograms from an optic tract "on" fiber. These responses consisted of an initial sharp burst of spikes followed by a decrement in firing which reached zero for short, low-intensity stimuli (lower, left-hand corner). This decrement was followed by a period of rebound firing which was often complex.

Figure 7 shows that equivalent responses occurred for stimuli of equal intensity-duration products (stimulus $\leqslant 500 \mathrm{msec}$, the longest tested) (cf. the 5-msec, $10^{4}-\mathrm{Td}$ response with the 50-msec, $10^{3}-\mathrm{Td}$ response). In most cases, the response equivalence was quite complete. In some examples, however (e.g., the 5-msec, $10^{2}$-Td response compared with the 50 -msec, 10-Td response), the equivalence was less than perfect.

\section{Optic Tract “Off" Fiber}

Figure 8 displays data from an optic tract "off", fiber. The initial response was a decrement in firing which usually reached zero. This was followed by rebound firing of substantial magnitude. As with optic tract "on" fibers, the late components were often complex. Fairly good response equivalence, defined by visual superimposability, for different stimuli of equal intensity-duration product was observed at durations as long as $500 \mathrm{msec}$ (cf. $5 \mathrm{msec}, 10^{4} \mathrm{Td}$ with $50 \mathrm{msec}$, $\left.10^{3} \mathrm{Td}\right)$.

\section{Comparisons Between Lateral Geniculate and Optic Tract Responses}

Figure 9 presents the data on energy summation. Equivalent responses from a single cell are plotted on each line. (Responses were deemed to be equivalent when they could be superimposed. Equivalent re-

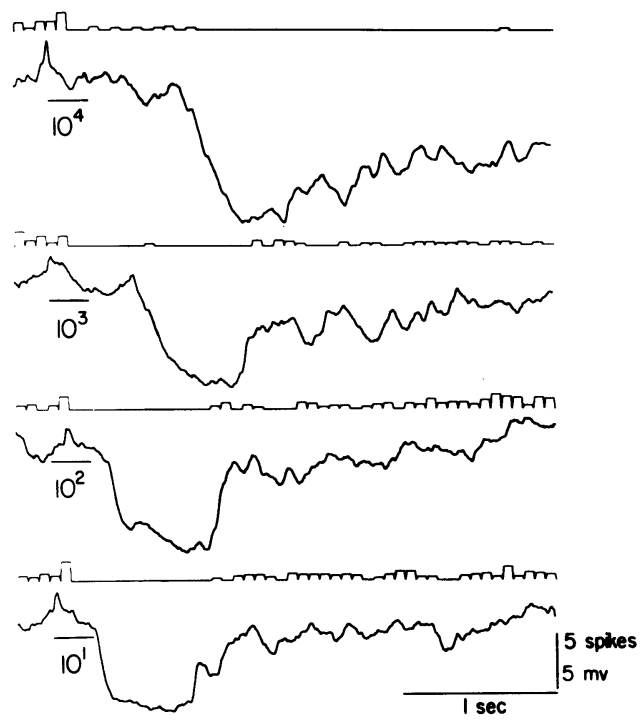

Figure 6. Effect of varying light intensity on a lateral geniculate "off" cell. Light duration of $250 \mathrm{msec}$ is indicated by the solid bar at the left immediately beneath each averaged membrane response. Other aspects of this figure as described in Figure 5. 

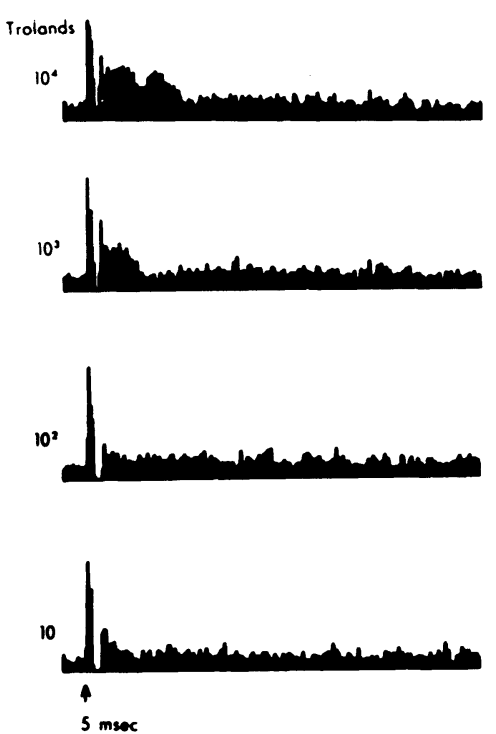
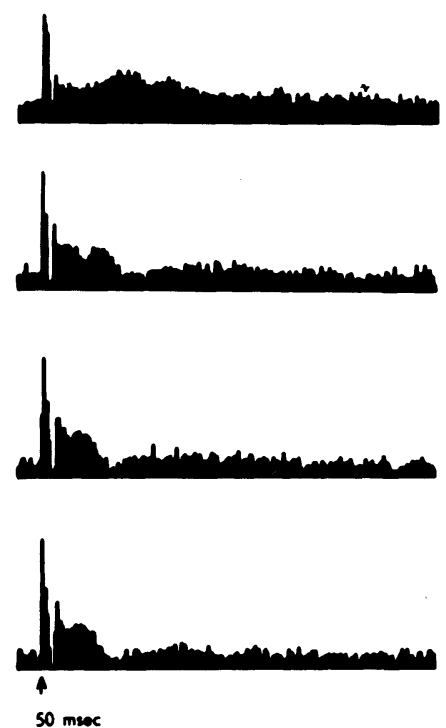
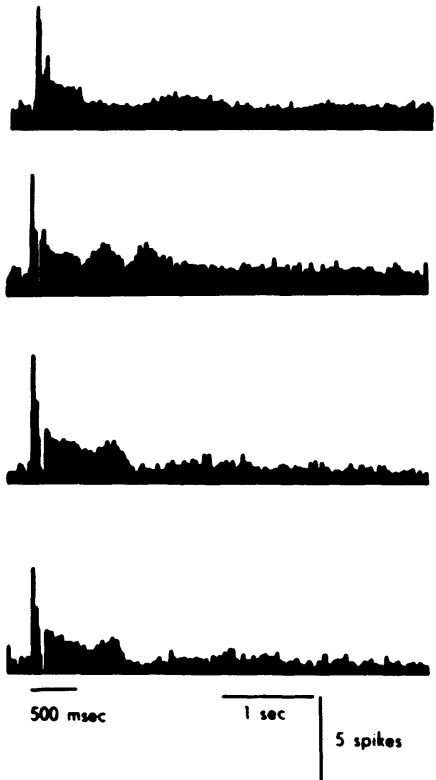

Figure 7. Effects of varying intensity and duration on spike discharge frequency of an optic tract "on" fiber. Duration is indicated at the bottom of each column, intensity at the left of each row. These histograms are arithmetical averages of 10 consecutive responses. Bin width: 20 msec.

sponses for all equal energy pairs are shown.) In Figure 9A, equivalent response data for three lateral geniculate "on" cells are plotted. In Figure 9B, similar plots are presented for three optic tract units (two "on" units, one "off" unit).

There were many instances, within the lateral geniculate data, of equivalent responses evoked by stimulus pairs of unequal energy. When this occurred, however, at least one stimulus of each of these pairs was of a greater duration than that over which energy summation was found to occur. By this means, the limits of the period of energy summation were defined.

The envelopes of the peristimulus frequency histograms of optic tract fibers show a close correspondence with some lateral geniculate membrane responses for about $150 \mathrm{msec}$ after the stimulus. Figure 10 illustrates this relationship. The averaged membrane responses were all computed from the same lateral geniculate cell, and the averaged histograms from the same optic tract
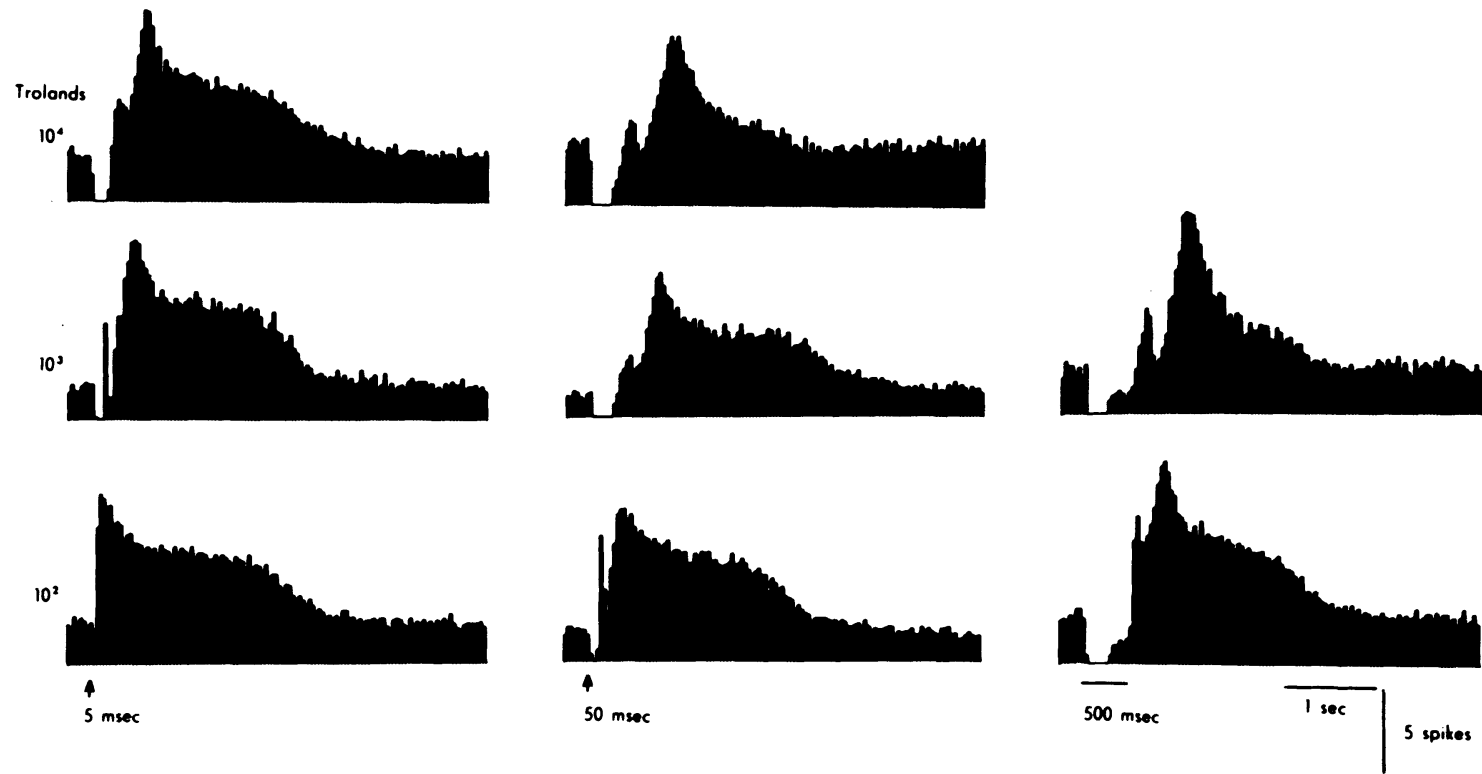

Figure 8. Effects of varying intensity and duration on spike discharge frequency of an optic tract "off" fiber. Duration is indicated at the bottom of each column, intensity at the left of each row. Each histogram is an average of 10 consecutive responses. Bin width: 40 msec. 

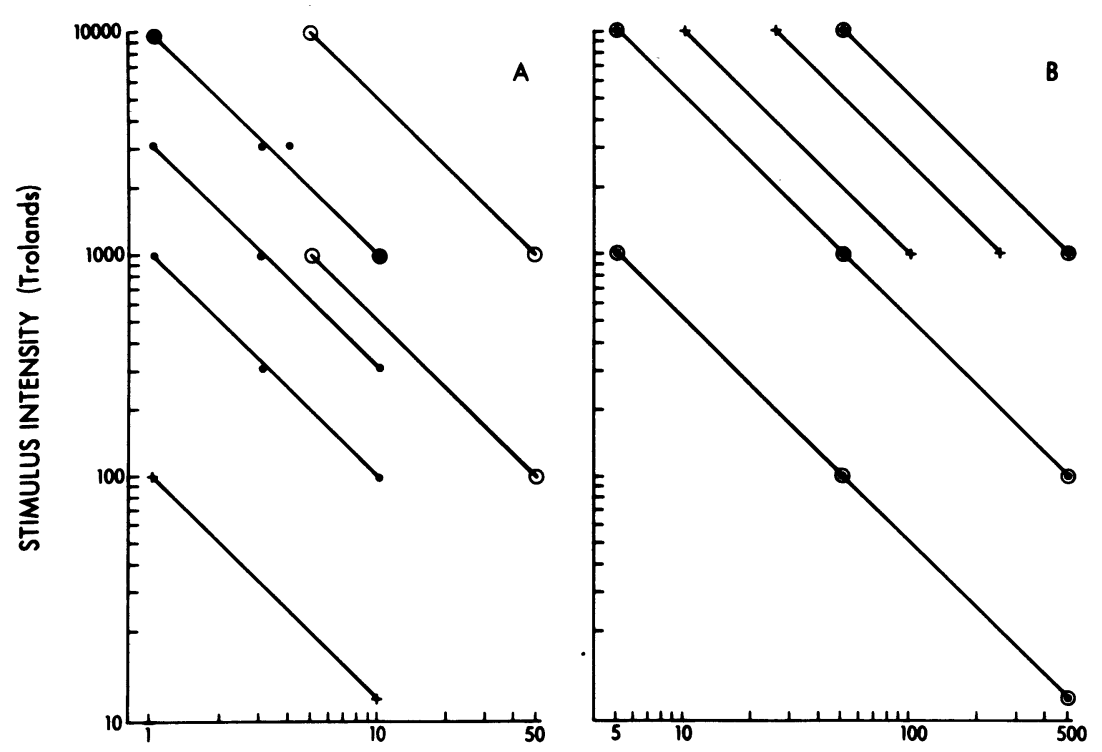

Figure 9. Response equivalence for equalenergy stimuli: (A) Date from three lateral geniculate "on" cells. One cell is designated on the graph by an open circle $(O)$, another as a solid dot $(\cdot)$, and the third as an $x$. The second line from the top incorporates responses from all three neurons. Ordinate and abscissa are in logarithmic units. Note that the time scale on the abscissa extends to 50 msec. (B) Data from three optic tract fibers. The unit designated with a solid dot is an "off" response fiber, the circle and the $x$ are "on" fibers. The top line is based on all three units. Ordinate and abscissa are in logarithmic units. Note that the time scale on the abscissa extends to 500 msec, while that on (A) extends to 50 msec.

STIMULUS DURATION (msec)

fiber. The figure shows four stimulus conditions, with adjacent optic tract and lateral geniculate responses evoked by similar stimuli. The initial response of the optic tract fiber is an increase in firing frequency followed by a pause in firing and then by a rebound discharge. Correspondingly, the lateral geniculate response consists of a depolarization followed by a hyperpolarization and then a series of depolarizing and hyperpolarizing potentials. These relationships suggest that the input from the optic tract "on" fibers accounts for the responses of the lateral geniculate "on" cells over the early ( $\leqslant 150 \mathrm{msec}$ ) poststimulus period. It further seems likely that the early hyperpolarization seen in responses of the lateral geniculate "on" cells is due to disfacilitation of input, rather than to a direct inhibitory hyperpolarization.

The same correspondences appear to hold for some "off" cells as well (cf. Figure 8 with Figures 5 and 6).

While patterns recorded from cells of the lateral geniculate body show many consistent features, one is left with the impression that variation of only two stimulus parameters, intensity and duration, result in a great complexity of response. This complexity is illustrated in Figure 11, which is composed of five segments, all of which involve intracellular recording from the same neuron under different stimulus conditions. The averaged responses in each segment were evoked by stimuli of constant intensity, but different durations. The stimulus intensity of each segment is indicated immediately below that segment. The stimulus occurs at the arrow on the front of each segment, and the duration is indicated on the left-hand side of each segment. The segments are drawn in perspective, so that the amplitude and length of the traces decrease proportionately from bottom to top. While the phenomena of energy summation provide a correlate of some of the response complexity shown, they by no means are able to provide an explanation for all of it.

\section{DISCUSSION}

The discussion will be devoted to the following points: (A) the effects of the intensity and duration of the stimulus; (B) a comparison of intracellular

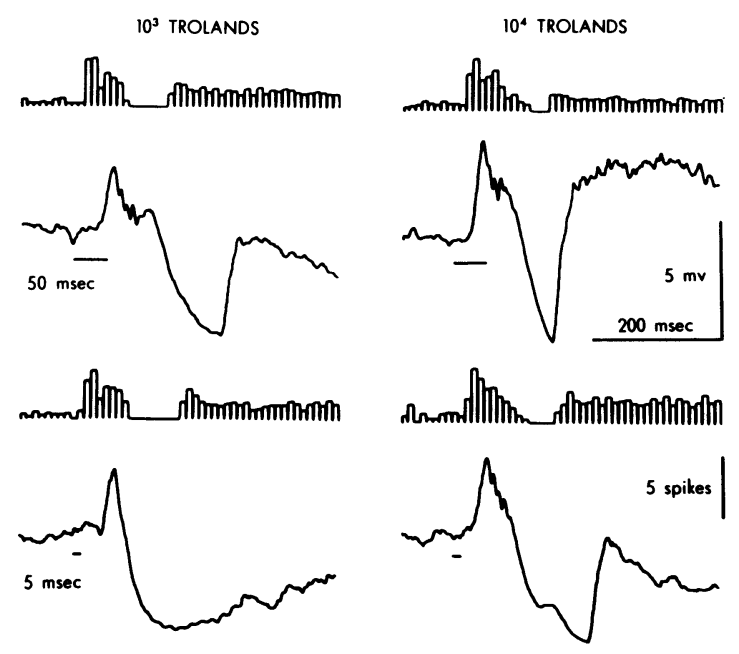

Figure 10. Comparison between optic tract and lateral geniculate The averaged histograms represent data from a single optic tract fiber, the averaged membrane responses data from a single lateral geniculate cell. Note the correspondence of the early components. Bin width: 10 msec. 

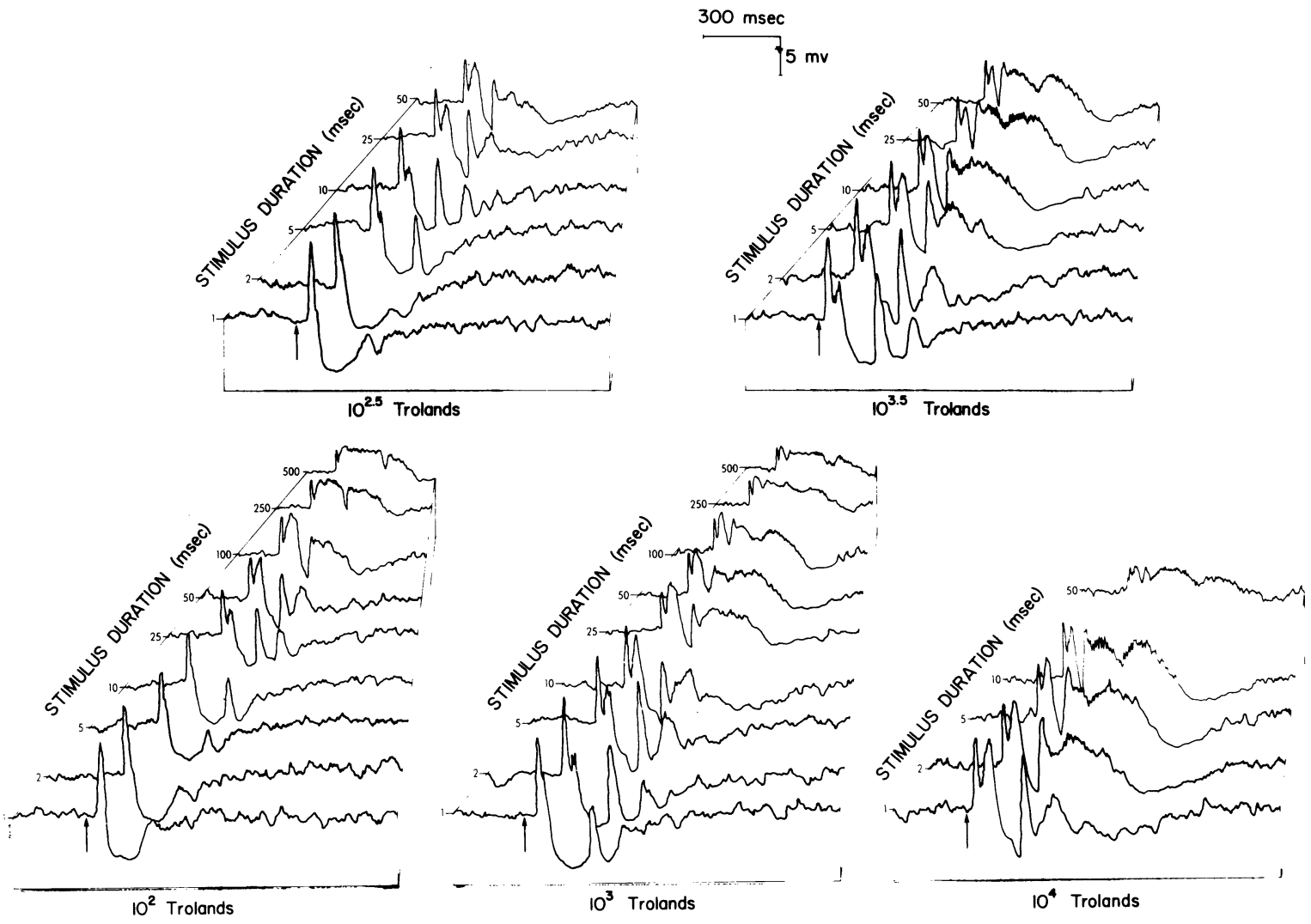

Figure 11. Composite of averaged membrane responses to variations in stimulus intensity and duration of a lateral geniculate "on" cell: To convey an appreciation of changes in response complexity with variation in the stimulus parameters, these tracings have been drawn in a three-dimensional perspective. Each segment represents a different intensity, indicated at the bottom of that segment. Stimulus duration increases as the segment recedes in perspective. Stimulus onset is indicated by the arrow on the front trace of each segment. These figures are drawn in a true perspective so that amplitude and duration are proportionately decreased from front to back. The calibrations of amplitude and time at the top of the figure apply to the front panel of each segment.

lateral geniculate recordings and extracellular optic tract recordings; $(C)$ the extent to which the results may be generalized to other experimental procedures; and (D) the relationships of the electrophysiological results with results obtained from the human psychophysical literature.

\section{Effects of Intensity and Duration of the \\ Light Stimulus}

Intensity effects. For a fixed stimulus duration, increasing stimulus intensity generally introduced a series of changes in lateral geniculate recordings. The first effect was an increase in the amplitude of the response components. With further increases, later components were added to the response. These increased up to a point both in amplitude and in complexity. Finally, with further increases, these complex responses were altered into an extended, rather uniform depolarization in the case of "on" cells, and an extended hyperpolarization in the case of "off" cells. Optic tract response patterns were generally much less complex, the later portions consisting of an afterdischarge for both "on" and "off" fibers. The patterns which were observed in these late components were reliable, but relatively difficult to detect in a single response.

Duration effects. The duration of the light flash also has a major effect on the response generated, especially in the lateral geniculate cells. For a given stimulus intensity, a short stimulus ( $\leqslant 10 \mathrm{msec}$ ) typically evoked a postsynaptic depolarization followed by a hyperpolarization in "on" cells; in "off" cells, the initial depolarization was not always present. In most cells, complex responses consisting of several components appeared at shorter stimulus durations. With increasing duration, these merged into simpler depolarized or hyperpolarized responses. Thus, as duration was increased, the response was transformed to a classical "on" or "off" pattern. The stimulus duration for this transformation ranged from approximately 100 to $1,000 \mathrm{msec}$, depending on the particular cell. Complex responses to diffuse light resembling these have been reported by Fuster, Creutzfeldt, and Straschill 
(1965) (intracellular recordings) and Grüsser and Saur (1960) (extracellular recordings).

The duration of the stimulus may play a somewhat lesser role in the development of responses of the optic tract fibers. The late components of these responses consist of an afterdischarge which seems to be entirely determined by the energy of the evoking flash.

Limits of energy summation. A striking result of this work is that the duration of the period of energy summation differed depending on whether the recording was made in the optic tract or the lateral geniculate. All equivalent responses considered here were evoked by equal-energy pairs. The maximum duration of the period of energy summation for cat lateral geniculate nucleus cells ranges from 10 to $50 \mathrm{msec}$, depending upon the cell. The maximum duration of the period of energy summation found for optic tract fibers was at least 10 times longer, and response equivalence was found at the longest duration $(500 \mathrm{msec})$ for which the optic tract cells were tested.

These results complement those of Levick and Zacks (1970), who studied energy summation by means of the equivalent response method, but stimulated only the center of the receptive fields of cat retinal ganglion cells. They employed levels of light intensity which ranged from that just sufficient to evoke a threshold response to 2,450 scotopic trolands and demonstrated energy summation in one cell for stimuli as long as $128 \mathrm{msec}$ (the longest tested). Their data suggest that the results reported here for optic tract fibers may be generalized to threshold levels of light intensity.

Equivalent responses to equal-energy stimulus pairs were examined in three "on" fibers and one "off" fiber in the optic tract (Figure 9). No equivalent responses to equal-energy stimulus pairs were found for lateral geniculate "off" cells. This may be due to the fact that no data were available for which both members of equal-energy stimulus pairs were less than $10 \mathrm{msec}$ in duration.

\section{Comparisons Between Optic Tract and \\ Lateral Geniculate Neurophysiology}

In early components (about $150 \mathrm{msec}$ ), the optic tract and lateral geniculate potentials show a close correspondence (cf. Figure 10). This suggests that these early components are codetermined, the excitatory optic tract responses giving rise to the excitatory potentials in the lateral geniculate, and the LG hyperpolarizations probably being due to a disfacilitation. In this view, the later components of the lateral geniculate response are due to the contributions of interneurons and to input from the visual cortex and midbrain reticular formation (Angel, Magni, \& Strata, 1967; Meulders \&
Godfraind, 1969; Szentagothai, 1963).

\section{Generalizability of These Results}

Light intensity level. Rushton and Powell (1972) have demonstrated in humans that a light of about $5.24 \mathrm{log}$ troland seconds is required to bleach about $2 \%$ of the retinal rhodopsin, which, in turn, raises the initial threshold about $0.6 \log$ units. This quantity of light is far above that employed in these experiments on a single trial, and was seldom approached on any series of trials. Thus, we may conclude that the responses observed probably bear no relation to the bleaching of $2 \%$ of all retinal rhodopsin. This quantity of rhodopsin represents the limits of Rushton's measurement techniques.

Relation of responses obtained from diffuse stimuli to those obtained in receptive field studies. Responses evoked from either lateral geniculate or optic tract units by diffuse light flashes are very similar to those evoked by light stimulation of the center of the receptive field (e.g., Kuffler, 1953). This finding has been supported quantitatively for the case of the squirrel monkey lateral geniculate body (Jacobs \& Yolton, 1970), where 98\% of the units show center-like responses to diffuse stimulation. Our responses may be considered to be primarily due to functional stimulation of the center of the receptive fields alone.

This conclusion is strengthened by the results of Barlow, Fitzhugh, and Kuffler (1957) for the case of retinal ganglion cells. They showed that after extensive dark adaptation, the contribution of the surround to the total response becomes undetectable. Our responses were evoked under conditions of no background illumination.

Similarities between cat and human visual neurobiology. While it is obvious that cats are different from people, their visual systems, with the exception of cats' relative inability to distinguish colors (Pearlman \& Daw, 1971), are remarkably similar. (Primate color vision is probably associated with the dorsal three layers of the lateral geniculate body, which are absent in cats.) Anatomical similarities between cat and human visual systems are in other respects quite extensive, extending to the level of the synaptic ultrastructure of the lateral geniculate (Szentagothai, 1963).

\section{Relations of the Neurophysiological Results \\ to Human Visual Psychophysics}

We have used the method of response equivalence to estimate the duration of the period of energy summation for responses at the level of the lateral geniculate body and optic tract of cats. The duration of the period of energy summation was found to be $10-50 \mathrm{msec}$ for cells in the lateral geniculate, and at least $500 \mathrm{msec}$ for optic tract fibers. Thus, the lateral 
geniculate data provided much shorter estimates of the period of energy summation. The stimulus intensities which were used were within the range employed by Aiba and Stevens (1964) in their brightness matching study of human psychophysical response. Therefore, it seems fair to suggest that the neurophysiological processes at the level of the lateral geniculate provide the most peripheral correlate of brightness matching phenomena.

Compared to brightness matching, the period of energy summation measured by detection methods covers a wider range of durations. Barlow (1958) reported psychophysical detection experiments with periods of energy summation as long as $1 \mathrm{sec}$ for conditions employing dark adaptation and small stimuli. Levick and Zacks (1970) report receptive field studies of retinal ganglion cells. Stimulating only the center of the receptive fields, they observed equivalent responses with threshold-level stimuli as long as $128 \mathrm{msec}$. One prominent feature of these responses was the relation between light intensity and response latency. The latency at threshold was about twice as long as at $2,450 \mathrm{Td}$. The total duration of the equivalent responses recorded from the optic tract is probably too long to provide a parallel for the judgment of the presence or absence of the light stimulus. The reaction time in humans for this detection process is about $200 \mathrm{msec}$ for the short suprathreshold stimuli reported here (Vaughn, Costa, \& Gilden, 1966). While the duration of the response was much too long to provide a simple parallel with the detection process, the variation in latency does suggest that the initial components of the response, which appear to be of similar configuration, carry information necessary to the detection process.

Where a human psychophysical judgment is involved, both detectability and brightness information are probably relayed to the cortex via the lateral geniculate body. How both kinds of information may be transmitted is suggested by Figure 10. The early excitation of the optic tract represented by the initial increase in firing is transmitted more or less intact by the lateral geniculate neuron. This direct transmission would constitute the detectability information. Following this initial parallel in excitation, a dissociation between the lateral geniculate membrane response and the optic tract firing rate occurs. Thus, the brightness information may be found in the subsequent duration and pattern of the hyperpolarizing and depolarizing membrane shifts of the lateral geniculate neuron.

Further support for the idea that these differences can be represented in psychophysical judgments has been provided by Zacks (1970), who plotted psychometric functions for equal-energy stimuli ( 4 and $81 \mathrm{msec}$ ) and then measured their discriminability. He found that, as the stimulus intensity increased, the flashes became more detectable and also more discriminable.

\section{REFERENCES}

Aiba, T. S., \& Stevens, S. S. Relation of brightness to duration and luminance under light- and dark-adaptation. Vision Research, 1964, 4, 391-401.

Angel, A., Magni, F., \& Strata, P. The excitability of optic nerve terminals in the lateral geniculate nucleus after stimulation of visual cortex. Archives italienes de Biologie, 1967, 105, 104-117.

BARLOw, H. B. Temporal and spatial summation in human vision at different background intensities. Journal of Physiology, 1958, 141, 337-350.

Barlow, H. B., Fitzhugh, R., \& Kuffler, S. W. Change of organization in the receptive fields of the cat's retina during dark adaptation. Journal of Physiology, 1957, 137, 338-354.

Fuster, J. M., Creutzfeldt, O. D., \& Straschill, M. Intracellular recording of neuronal activity in the visual system. Zeitschrift für Vergleichende Physiologie, 1965, 49, 605-622.

GRüsser, O. J., \& SAUR, G. Monoculare und binoculare Lichtreizung enzeiner Neurone in Geniculatum laterale der Katze. Pflugers Archives, 1960, 271, 595-612.

Hull, C. D., Bernardi, G., Price, D. D., \& Buchwald, N. A. Intracellular responses of caudate neurons to temporally and spatially combined stimuli. Experimental Neurology, 1973, 38, 324-336.

JACOBS, G. H., \& Yolton, R.' L. Center-surround balance in receptive fields of cells in the lateral geniculate nucleus. Vision Research, 1970, 10, 1127-1144.

KUFFLER, S. W. Discharge patterns and functional organization of mammalian retina. Journal of Neurophysiology, 1953, 16, 37-68.

LE GRAND, Y. Light, color and vision (2nd ed.) (Trans. by R. W. G. Hunt, J. W. T. Walsh, \& F. R. W. Hunt). London: Chapman and Hall, 1968.

LeVICK, W. R., \& ZACKs, J. L. Responses of cat retinal ganglion cells to brief flashes of light. Journal of Physiology, 1970, 206, 677-700.

Meulders, M., \& Godfraind, J. M. Influence du reveil d'origine reticulaire sur l'etendue des champs visuels des neurones de la region genouillee chez le chat avec cerveau intact ou avec cerveau isole. Experimental Brain Research, 1969, 9, 201-220.

Pearlman, A. L., \& Daw, N. W. Behavioral and neurophysiological studies on cat color vision. International Journal of Neuroscience, 1971, 1, 357-360.

Rushton, W. A. H., \& Powell, D. S. The rhodopsin content and the visual threshold of human rods. Vision Research, 1972, 12, 1073-1081.

Szentagothai, J. The structure of the synapse in the lateral geniculate body. Acta Anatomy (Basel), 1963, 55, 166-185.

TASAKI, K., Tsukahara, Y., ITo, S., WAYNeR, M. J., \& Yu, W. Y. A simple, direct and rapid method for filling microelectrodes. Physiology and Behavior, 1968, 3, 1009-1010.

Vaughn, H. G., JR., Costa, L. D., \& Gilden, L. The functional relation of visual evoked response and reaction time to stimulus intensity. Vision Research, 1966, 6, 645-656.

Westheimer, G. The Maxwellian view. Vision Research, 1966, 6, 669-682.

Young, D. N., JR. Lateral geniculate postsynaptic responses to light stimuli and their relation to energy summation and visual persistence in human visual psychophysics. (Doctoral dissertation, The University of California at Los Angeles, 1973). Dissertation Abstracts International, 1973, 34, 3124B. (University Microfilm No. 7332088).

ZACKs, J. L. Temporal summation phenomena at threshold: Their relation to visual mechanisms. Science, 1970, 170, 197-199.

(Received for publication June 1, 1975; revision accepted December 19, 1975.) 